\title{
The kinship of apes and people
}

\begin{abstract}
An unpromising argument that apes should forthwith be regarded as equal members with people of a single community deserves a wide hearing, not because it is likely to happen but because it is constructively provoking.
\end{abstract}

To borrow from the bookmakers, what follows is a turn-up for the book. Not often is it possible to pick up a volume which, on the strength of its preface and blurb, promises to be an unmitigated irritant, and then to find that the text is compulsive reading even if the argument falls short of being compelling. Yet that is the case with The Great Ape Project, edited by Paola Cavalieri and Peter Singer (Fourth Estate, London, 1993). Singer is the better known of the two editors, and he chiefly as the one who has made the term speciesism, which stands in relation to animal species as does racism to the human race, one of the most common terms of abuse in the vocabulary of the animal rights movement. (The inventor of the term is one Richard D. Ryder, described as a British lobbyist in the Liberal Democrat cause, who is one of the 34 contributors to this symposium volume - and the briefest.)

The reason why the book threatens to be an irritant is that it begins with a tract, or manifesto, with the sententious title "A declaration on great apes". (The reasons for the lack of a definite article before "great apes" will become clear.) The manifesto says that the time has come to admit into the "community of equals" not only members of the human species but orang-utans (Pongo pygmaeus), gorillas (Gorilla gorilla) and chimpanzees of both known species (Pan troglodytes and $P$. paniscus). And the community of equals? That is the set of living creatures belonging to these species to all of whom the respect (in the legal sense) at present accorded to members of the species Homo sapiens is to be extended.

Varying the terms of the Declaration of Independence only slightly, the authors specify that the moral principle of the community of equals should be life, liberty and the "prohibition of torture". A few caveats quickly arise. Great apes, human or otherwise, should not be killed "except..., for example, in self defence". To deprive members of the community of equals of liberty is not allowed except for their own protection or that of others, in which case there must be an appeals procedure, if necessary by advocates as in the present legal treatment of members of the human community. And "no torture" means "no experiments without informed consent", which only adult members of the relatively articulate Homo sapiens can provide.

Just how fanciful is the notion of the community of equals? The two editors (who add that all their contributors "subscribe" to their declaration), acknowledge that not all members of Homo sapiens now benefit from their moral principles, so that there may be little enthusiasm for extending them to other species. But on laboratory experiments with non-human apes, they insist that the balance of the argument has so shifted that the onus of proof lies with the experimenters. (Neither "vivisectionist" nor its variant "vivisector" is conspicuous in the text.) To guard their rear against the likes of those who are forever "liberating" beagle dogs from laboratories, they offer the community of equals as a possible first step towards the inclusion of other species. (But that has not convinced Steve F. Sapontzis of the California State University, who protests that singling out the non-human apes for special treatment simply perpetuates the errors of speciesism.)

This is an arid starting-point for a good read. There are two reasons why the book succeeds in spite of its agenda. One is that most of the contributors have taken their assignments seriously, raising a string of interesting questions in the process. Another is that the bulk of the book necessarily encircles a question that becomes more challenging with each year that passes: what precisely are the behavioural differences between people and other apes (to follow the Cavalieri/ Singer idiom for much of what follows), what features of the genome do they represent and how did they arise genetically?

That said, most of the contributors enter fully into the spirit of the agenda set for them, which is to demonstrate the kinship between people and apes. There is plenty of material. People who have spent time with chimpanzees, such as Jane Goodall and Toshisada Nishida, tell what that is like with humour.

Those who converse with apes (by signlanguage, not natural for either party) and who judge their emotional states by looking into their eyes occasionally protest too much that they are aware of the pitfalls of anthropomorphism, but that does not crab their tales. That apes (not just chimpanzees), or at least some of them, can communicate with people must be taken as a fact. That they can do so with a measure of abstraction, distinguishing between the first, second and third persons, is something to brood upon.

Richard Dawkins has the most elegant resolution of that question: the sharp discontinuities attributed by taxonomists to the gulfs that separate species are, in the sweep of evolution, an illusion.

As one goes back along an evolutionary tree, or a cladogram, the distinctions between extant species are blurred, and who can tell with confidence which existing popu- lation of a supposedly single species harbours the founders of further speciation?

Even so, Dawkins is not the only contributor to marvel at the shortness of the timespan occupied by the evolution of the apes; 15 million years lumps us all (in the Singer idiom) together, an extra 5 million years would include the gibbons as well. And everybody marvels at the homology of cognate genes among the apes, whence Jared Diamond's name "the third chimpanzee" for people and his question how visitors to zoos will react when the chimpanzees are housed in cages labelled Homo troglodytes.

But, curiously, nobody makes much of the circumstance that people differ from other apes in having only 46 chromosomes, not 48 . That is surely relevant to the agenda of the community of equals in two practical ways: it is a reminder that not only the structure of the genes matters, but also their arrangement and, presumably, coordination. And it suggests that genome sequencing may also eventually explain why some of the phenotypic differences between different apes (Singer's idiom) are sharper than homology would suggest.

Meanwhile, readers must be content with what philosophers, sociologists and lawyers have to say. Indeed, they turn out to be more interesting than the biologists, no doubt because they cannot dodge the management of the community of equals. Their consensus is that it is in principle like the management of human society, in which the disadvantaged deserve respect and compassion but in which there are also many more of them, the members of what we persist in calling different species.

In the Latin sense of the word, the community of equals is an admirable cause. It is also an interesting and provoking light in which to put relationships with other animals. One of the questions that arise is whether, in a future community of that kind, the smarter set would compassionately embark on improving the genetic lot of the disadvantaged, and what the consequences would be. Most of the contributors to this symposium would probably be offended by the thought, but when the techniques are safely available, it is not easy to see why they should be. Much the same dilemma arises already in the question whether isolated tribes in the Amazon should be helped to a more modern way of life; the tribesmen are usually more eager for change than those who might help them. That is what undermines the community of equals we like to think we have already.

John Maddox 